\title{
Five Trends in Earth Sciences
}

The ongoing activities of IUGS reflect both new trends in Earth Sciences and traditional tasks such as the production of general or special geological maps or the definition of international standards in petrology or stratigraphy. The first trend is that of ongoing specialization, the unavoidable price we must all pay for scientific progress. Being aware of specialization should encourage us all the more to bring specialists together, but if our language is incomprehensible to colleagues from other areas of the earth sciences, we shall increase the gap of understanding and diminish the interest and sympathy from outside. More dramatically: we would increase the gap between science and the public, one of the major dangers of our time, for we need to present essential messages in order not to be completely lost in the deafening noise of an information society.

The second trend, as I see it as a marine geologist, is the transgression of ideas and methods from the oceans to the continents. The historical and revolutionary results of continuous reflection seismics and magnetic measurements aboard ships together with the geological evaluation of ocean drilling are so stimulating that plate tectonics and sea floor spreading are now widely discussed. Many mafic rocks and greenstone belts have now been redefined as former ocean bottoms: What a wonderful tool are the sort of geological tourists called terranes, and what good luck that so many problems have disappeared in subduction zones!

Transgressions of ideas and transgressions of methods: Continuous reflection seismics and other geophysical methods as well as continental deep drilling projects are pretentious children of their marine parents. These have opened the door for earth sciences to become Big Sciences, too. And this leads to my third trend.

Vany earth scientists are strongly individualistic, with field geologists defining their territories and mineralogists and paleontologists protecting new minerals and fossils. Big science, however, needs organization, cooperation and teamwork. Geophysicists are normally better trained for that, perhaps because they have intimate relations with physicists who are so extremely effective in organizing big projects - and big money, too, as exemplified by big accelerators, satellites and space labs. We, too, should be courageous enough to ask also for crustal labs to study fluid/rock interactions and other processes as laid open by deep drilling. But big money should be justified by big problems to be solved and by excellent cooperation.

The fourth trend is the ongoing quantification in earth sciences. Qualitatively coral reefs tell us that they are happy in tropical seas, but quantitatively they tell us much more about temperature, salinity, light conditions and other climatic factors. Perovskite and other minerals are happy in the mantle, but they can give us details about climate too, namely about the deeper climates in our Earth. We are beginning to measure and use the speed of geological processes, and we are trying quantitatively to reconstruct the evolution of sedimentary basins so that we can explore more effectively for hydrocarbons. We are beginning to determine the climatic fluctuations of our atmosphere under the influence of small astronomical changes of the Earth, and this may open a new stratigraphic method using Milankovich Cycles far back into Earth history. And in order to understand some of these processes we are increasingly using experiments.

But we should not forget that our strength is our Earth in its proper sense. Together with many of you, I am always fighting for field geology and for students with hammers and not only with lab coats. We should not forget that our essential target is the history of our planet, based on quantitative physical, chemical and biological laws, though obscured by many unexpected events resulting from the endless and complex combinations of all these factors.

The complexity of factors we have to deal with may be the reason why the fifth trend is not visible to everybody. We are trying to decipher Earth history and to understand presently ongoing processes. In spite of our professional training to look back, we must try to look ahead too, because our assistance is needed to solve many urgent problems resulting from the rapid but unequal increase in global population and the unequal distribution of material goods. This begins with reliable data about mineral, water and soil resources. In general, we are trained to estimate carefully the reserves of an oilfield or a mine, but we must work towards a capacity to gauge world reserves, both for hydrocarbons and ores in general.

On the other hand, we have a grand design for natural hazards such as earthquakes and volcanic eruptions. They are concentrated at plate boundaries - if they are not so crazy as to occur at intraplate situations. But on a local scale we are usually lost, and we should encourage every possible refinement in the search for ways to predict earthquakes and volcanic eruptions, as well as a better understanding of climatic variations.

We all know that fewer people are prepared to accept acts of nature as acts of God or of fate. Increasingly science is blamed for not having given a timely warning. We have to explain very honestly to the public the state of our knowledge and of our ignorance, which may never be overcome because of all the complex interrelations involved. Indeed, geological complexity is often the cause of very cautious, even vague expert opinions. Many Chinese poems are vague, too, perhaps because the poet wants to stimulate creative ideas in others. Let us hope that our presently rather vague ideas, for example about climate variations, may likewise stimulate many new creative ideas.

E. Seibold

Past-President, IUGS Freiburg, F.R.G.

(Based on an address to the IUGS Executive Committee and the National Committee for China, Guangzhou, February 1988)

IN THE NEX T IS SUE

THE GEOLOGY OF SOUTH AMERICA

(A Special Issue on the Occasion of the 7th Latin

American Geological Congress) 